\title{
New Species of Adoxomyia (Kertész, 1907) (Diptera: Stratiomyidae) from Turkey
}

\author{
Turgay ÜSTÜNER \\ Department of Biology, Faculty of Science, Selçuk University, Selçuklu, Konya, 42100, \\ TURKEY \\ e-mail: tustuner@selcuk.edu.tr \\ ORCID ID: 0000-0002-0604-2346
}

\begin{abstract}
A new species of soldier flies (Diptera: Stratiomyidae), Adoxomyia hasbenlii sp. nov., is described from Turkey. The characters of the new species were examined and photos are presented, and the species-specific male terminalia is illustrated and compared with related species, Adoxomyia variabilis Krivosheina, 2016, and Adoxomyia ruficornis (Loew, 1873). An identification key to the related species of Adoxomyia is presented.
\end{abstract}

Key words: Stratiomyidae, Adoxomyia, new species, biodiversity, Turkey.

Üstüner, T. (2021). New Species of Adoxomyia (Kertész, 1907) (Diptera: Stratiomyidae) from Turkey, Journal of the Entomological Research Society, 23(1), 97-103. 


\section{INTRODUCTION}

The genus Adoxomyia (Kertész, 1907) belongs to the subfamily Clitellariinae in the family Stratiomyidae and includes over 40 described species that are distributed all over the world, including 20 species in the Palearctic region (Lindner, 1938; Woodley, 2001; Hauser, 2002; Nartshuk, 2004; Üstüner, 2012; Krivosheina, 2016; 2017; 2018). Thus far, 7 species belonging to the genus have been identified from Turkey (Üstüner \& Hasbenli, 2011; Üstüner, 2012). These species comprise A. aurovittata (Bigot, 1879); A. begreliensis Üstüner, 2012; A. cinerascens (Loew, 1873); A. dahlii (Meigen, 1830); A. obscuripennis (Loew, 1873); A. sarudnyi (Pleske, 1903); and A. palaestinensis Lindner, 1937.

The adult species of Adoxomyia are flies with a black body. The eyes, in males, are adjacent to each other. There is a very fine, hair-thin line between them; hence, they appear as though they are connected, while in females they are separated by a wide frons. The antennae, which have important distinguishing characters for the identification of the species, are thicker in the females than in the males. The flagellum of the antennae consists of 8 flagellomeres, but the shape and arrangement of the 4-6 flagellomeres differ significantly between species. In some species of this genus, the antennae are dark-colored, while some others are bi-colored. One of the important characters in the identification of the species of the genus is the structure of the genitalia. In the male genitalia, the middle protrusion (median process) of the synsternum and the shape of the dististylus differ according to the species.

\section{MATERIAL AND METHODS}

In this study, a new species belonging to the genus Adoxomyia was defined, based on 1 male and 2 female specimens. The specimens. The specimens were deposited in the collection of the Selçuk University, Department of Biology in Konya, Turkey. Illustrations of the specimens were made using a Leica stereomicroscope (Leica Microsystems, Wetzlar, Germany) with Integrated LED llumination and Digital 3 MP Camera Leica EZ4 D camera system and then imported into Adobe Photoshop CS9 (Adobe Inc., San Jose, CA, USA) for labeling and plate composition. One male and one female were dissected and the genitalia cleared in $\mathrm{KOH}$ overnight and placed in glass/plastic vials on the same pin as the specimen.

\section{Adoxomyia hasbenlii sp. $\mathrm{n}$.}

Material examined: Holotype: $\delta$ Turkey, Kayseri, Yahyalı, Between Yahyalı and Dikme Village, elev. $1404 \mathrm{~m}, 38^{\circ} 2^{\prime} \mathrm{N}, 35^{\circ} 23^{\prime} \mathrm{E}, 14.08 .2002$, leg.: T. Üstüner.

Paratypes: 19 Turkey: Kayseri, Yahyalı, Between Yahyalı and Dikme Village, elev. $1404 \mathrm{~m}, 38^{\circ} 2^{\prime} \mathrm{N}$, $35^{\circ} 23^{\prime} \mathrm{E}, 14 . \mathrm{VII} .2002$, leg.: T. Üstüner. 1 T Turkey: Konya, Bozkır, Karacahisar Village, Aygırdibi Location, elev. 1400 m, 17.08.2009, leg.: T. Üstüner.

Description: Male (Figs. 1-3, 7-9): Head semicircular in lateral view, completely black. Eyes contiguous, with erect, dense setae. Eyes pile black, almost as long as 
New Species of Adoxomyia

scape. Frons and face black, covered with dense black setae as long as total length of the scape and pedicel. Frons with a fine longitudinal grove. Grove extends from the top corner of frons triangle to the bases of the antennae. Postocular band developed, its width is about as wide as the 7th flagellomere long in dorsal view. Postocular band is as wide as the total length of the 6th and 7 th flagellomeres in the upper half of the head and as wide as the length of the first 2 antennal segments in the lower half of the head in lateral view. Postocular area covered with short, adpressed, silvery-white setae. Antenna (Fig. 3) as long as the length of the head and 2-colored, mainly darkened, but first 3 flagellomeres dark-reddish brown. The scape is about 1.5 times the length of the pedicel. Scape and pedicel with black hairs, approximately as long as 1.5 times the length of the pedicel. Three basal flagellomeres distinctly widened, their width slightly wider than the pedicel. From the fourth flagellomere on gradually narrowing. First flagellomere about 1.5 times as long as the 2 nd flagellomere (15:10). Fifth flagellomere about 1.5 times as long as the 4th, 6th, and 7th flagellomeres $(1.5: 1: 1: 1)$. Last flagellomere as thick as the width of the 7 th flagellomere, conical and equal in length to the 3 preceding flagellomeres combined. Height of the head nearly 1.5 times as long as the length of antennae (11.5:7.5).

Thorax black, with a small reddish-brown spot at the apex of humeral callus. Scutellum black with scutellar spines. Scutellar spines emerge from the corners of the posterior edge of the scutellum, about $1 / 3$ of the length of the scutellum and $1 / 3$ black basally, apical $2 / 3$ light brown, glabrous, obtuse, slightly arcuately bent inwards. Mesonotum and scutellum are covered with two types of setae: black, erect setae, slightly longer than the length of the scutellar spines, and with more dense, oblique, short, whitish setae. Legs mainly dark brown to black, except apical part of trochanters, knees, and ventral surface of tarsi light brown. Wing brownish, with dark veins. Haltere pale yellow with a darkened stalk.

Abdomen black with silvery-white setae along lateral sides of terga 1-3, on posterior margin of tergum 4, and over the entire surface of tergum 5. Genitalia: epandrium elongate; synsternum wide, elongate with triangular median process, dististylus thick, short, and pointed apex. The aedeagus is as in fig. 9.

Length of male: $6 \mathrm{~mm}$, wing $5 \mathrm{~mm}$.

Female (Figs. 4-6, 10-11): Head black. Eyes with dense, dark brown, erect hairs, eye piles about as long as pedicel. Frons about $1 / 3$ of head-width, slightly tapered towards the vertex. Postocular band strongly developed, its width is about as broad as the combined length of the 4th-7th flagellomeres measured in dorsal view. The postocular area black and covered with short, adpressed, and silvery-white hairs.

Antennae red and black (Fig. 6). Scape and pedicel black, first 3 flagellomeres bright reddish-brown. Scape slightly longer than pedicel (2:1.5). First 3 flagellomeres in female are wider than in male (1.5:1). First 3 flagellomeres of the flagellum distinctly widened, their width about 2 times the length of the pedicel. Last flagellomere slightly thickened at the base, narrowed and rounded at apex, equal in length to 3 preceding flagellomeres combined. Antennae are almost equal in length to the length of the head. 
Mesonotum and scutellum with more densely oblique, short, and whitish hairs, but not covered with black erect hairs as in male. Abdomen as those in male. Margins of tergites with narrow light brown edging.

Length of female: $6.2 \mathrm{~mm}$. Wing $4.5 \mathrm{~mm}$.

Etymology: The species was named in honor of Prof. Dr. Abdullah Hasbenli, a prominent entomologist who contributed significantly to the knowledge of Turkish and Palearctic diptera.

Key to the East Mediterranean Species of the genus Adoxomyia (Kertész, 1907)

1. Legs mainly black .2

-Legs bicolored or mainly yellow 7

2. Antenna entirely bicolored. .3

-Antenna entirely black. .5

3. Scutellum spines black basally, apically yellowish. Postocular band in dorsal view wide in male. Antennae of male dark.

-Scutellum spines black. Postocular band in dorsal view narrower in male. Antennae of male light brown first 3 flagellomere. A. ruficornis (Loew, 1873)

4. Antennae of male shorter than length of head and usually black. The last flagellomere thin and approximately $1 / 5$ of the total length of the flagellum....

A. variabilis Krivosheina, 2016

-Antennae of male almost equal to the length of the head and with the first three flagellomeres dark reddish-brown. The last flagellomere thick and approximately $1 / 4$ of the total length of the flagellum.

A. hasbenlii sp. $\mathrm{n}$.

5. Scutellar spines short, slender and bare, basal 3-4 flagellomeres in female

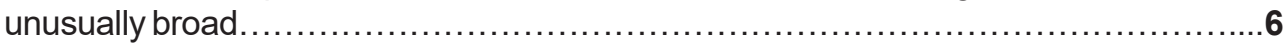

-Scutellar spines longer, thickened and haired, basal 3-4 flagellomeres not as broad. ..A. obscuripennis (Loew, 1873)

6. Female eyes black haired, postocular band wider than scape is long; male unknown A. hermonensis Lindner, 1975

-Female eyes white haired, postocular band as wide as scape is long A. transcaucasica Nartshuk, 2003

7. Legs entirely yellow A. sarudnyi (Pleske, 1903)

-Legs bicolored, at least femora black .......................................... 8

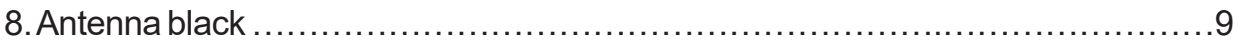

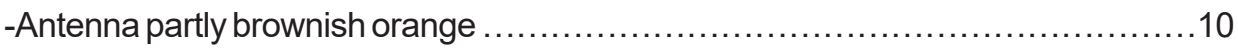

9. Body coarse and plump, abdomen with golden yellow hair patches

-Body slim and delicate, abdomen with silverish white hair patches.

A. aureovittata (Bigot, 1879) 
New Species of Adoxomyia

10. Scutellar spines black, third segment of antenna dark brown to black.

A. dahlii (Meigen, 1830)

-Scutellar spines yellow, third segment of antenna orange

11. Antenna 1.5 times as long as head, male flagellum cylindrical, female first three flagellomeres twice as broad as scape is long............. begreliensis Üstüner, 2012

-Antenna about as long as head, male and female flagellum distinctly swollen in middle. A. cinerascens (Loew, 1873)

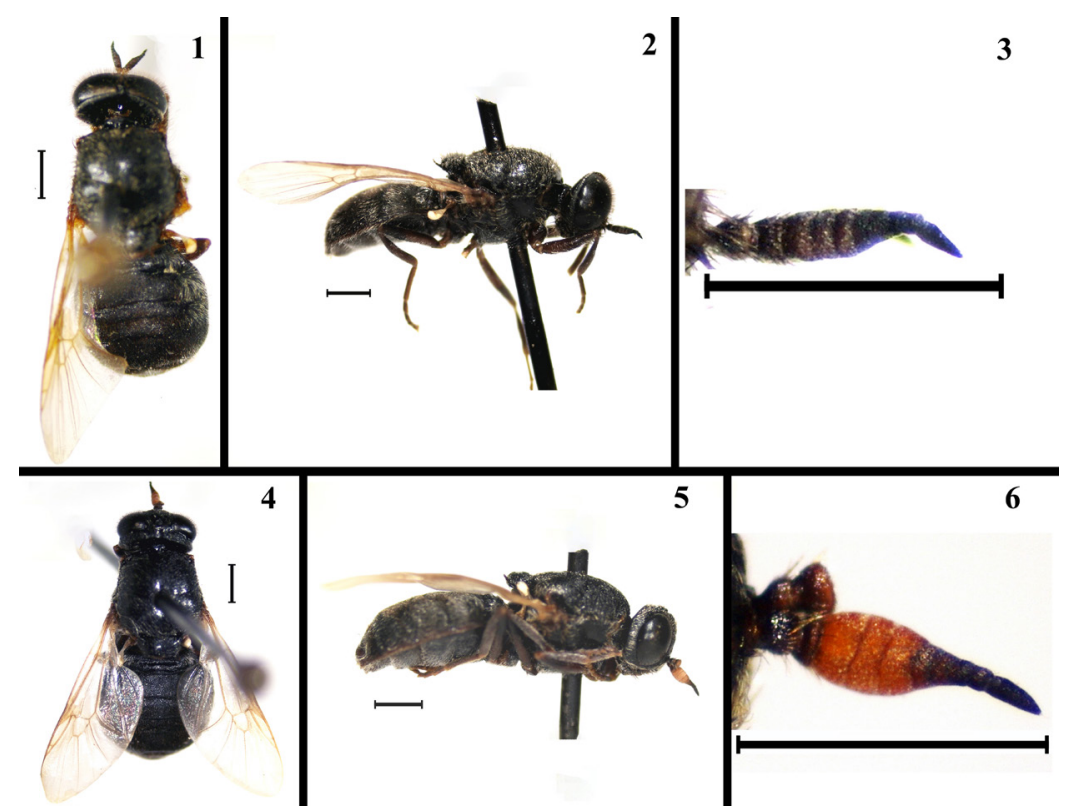

Figs. 1-6: Adoxomyia hasbenlii sp.n., adult: 1. Male dorsal view; 2. Male lateral view; 3. Male antennae; 4.

Female dorsal view; 5 . Female lateral view; 6 . Female antennae. Scale bar: $1 \mathrm{~mm}$
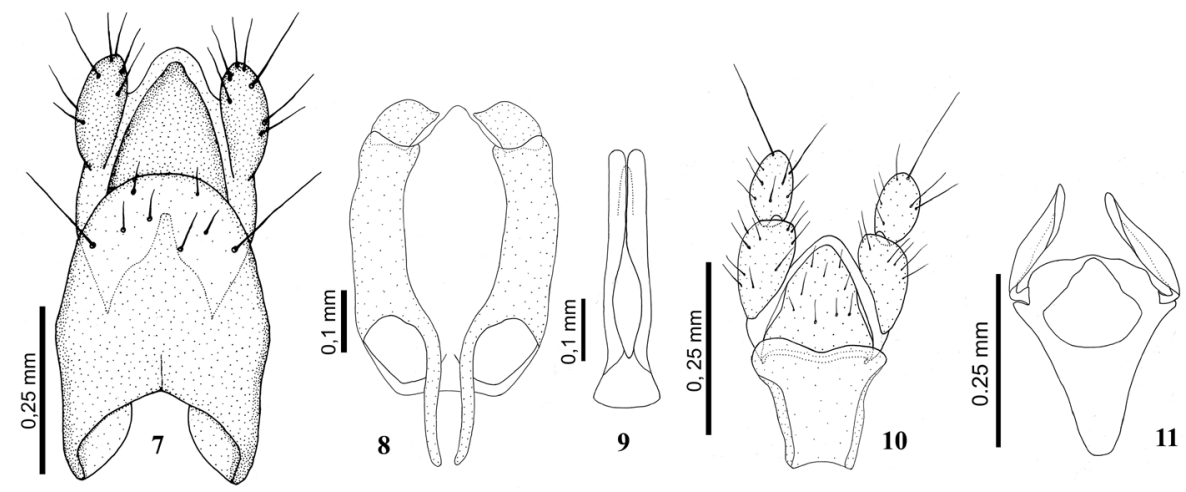

Figs. 7-11. Adoxomyia hasbenlii sp. $\mathrm{n}$ adult: 7. Male epandrium, dorsal view; 8. Male hypandrium view from inner side; 9 . Male aedegus; 10. Female terminal dorsal view; 11. Female genital furca. 


\section{DISCUSSION}

This new species is similar to Adoxomyia variabilis Krivosheina, 2016, described from Azerbaijan (Krivosheina, 2016). The length of the last flagellomere of Adoxomyia variabilis is approximately $1 / 5$ of the total length of the flagellum, while the length of the last flagellomere of Adoxomyia hasbenlii is approximately $1 / 4$ of the total length of the flagellum. The male antenna of Adoxomyia variabilis is slightly longer than the head and usually black, while that of Adoxomyia hasbenlii is almost equal to the length of the head, and the first 3 flagellomeres of the antennae flagellum are dark reddish-brown. The hypandrium of Adoxomyia variabilis is rectangular and its lateral edges are flat from the posterior to the anterior end, whereas the hypandrium of Adoxomyia hasbenlii is rectangular, its lateral edges are slightly inwardly recessed in the posterior part and slightly widen on the anterior part. The median process of the hypandrium of Adoxomyia variabilis is conical, rounded at the apical, and the dististylus of the hypandrium is a thick and pointed apex, while the median process of the hypandrium of Adoxomyia hasbenlii is conical, slightly pointed at the apically, and the dististylus is slightly thicker, stout, and pointed at the tip. In the female Adoxomyia variabilis, the ocellar tubercel is at the level of the posterior margin of the eye, while in the female Adoxomyia hasbenlii, the ocellar tubercel is slightly projected at the posterior edge of the eye. In the female Adoxomyia hasbenlii, the genital furca is different from that in Adoxomyia variabilis.

Adoxomyia hasbenlii is similar to Adoxomyia ruficornis in that its antennae are bi-colored. However, the antennae of Adoxomyia ruficornis are shorter than the head, the scutellar spines are black, and in dorsal view the postocular band in males is very thin (Krivosheina, 2017). When A. ruficornis male genital shape presented in the paper of Krivosheina (2017) is examined, it is seen that Adoxomyia hasbenlii and Adoxomyia ruficornis differ from each other by their different genital capsules.

\section{REFERENCES}

Hauser, M. (2002). A new species of Adoxomyia Kertész, 1907 (Diptera: Stratiomyidae) from Socotra, Yemen. Fauna of Arabia, 19, 463-466.

Krivosheina, N.P. (2016). Description of a new soldier-fly species of the genus Adoxomyia Kertesz, 1907 (Diptera, Stratiomyidae), based on adults and larvae from Azerbaijan. Entomological Review, 96-(3), 366-374.

Krivosheina, N.P. (2017). A review of the species of the genus Adoxomyia Kertész, 1907 (Diptera, Stratiomyidae) with bicolorous antennae and a description of a new species, Adoxomyia subruficornis sp. n. from Middle Asia. Entomological Review, 97(6), 832-846.

Krivosheina, N.P. (2018). New species of the genus Adoxomyia Kertész, 1907 (Diptera, Stratiomyidae) with black antennae. Entomological Review, 98(2), 228-239.

Lindner, E. (1938). 18. Stratiomyidae., In: Lindner E. (Ed.), Die Fliegen der Palaearktischen Region, 4(1), 1-218, E. Schweizert'sche Verlagsbuchhandlung, Stuttgart.

Nartshuk, E.P. (2004). New data on Adoxomyia Bezzi from the Caucasus and Eastern Europe (Diptera: Stratiomyidae). Zoosystematica Rossica, 12(2), 263-266.

Üstüner, T. \& Hasbenli, A. (2011). First record of the genus Adoxomyia (Diptera: Stratiomyidae) with four species from Turkey. Florida Entomologist, 94(1), 64-70. 
New Species of Adoxomyia

Üstüner, T. (2012). A new species of Adoxomyia (Diptera: Stratiomyidae) from Turkey. Florida Entomologist, 95(2), 338-343.

Woodley, N.E. (2001). A world catalog of the Stratiomyidae (Insecta: Diptera). Backhuys Publishers, Leiden, $474 \mathrm{pp}$. 